Dublin 3, Ireland.

References

1. Taylor D. Pharmacokinetic interactions involving clozapine. Br J Psychiatry 1997; 171: 109-12.

2. Jerling M, Lindstrom L, Bondesson $U$ et al. Fluvoxamine inhibition and carbamazepine induction of the metabolism of clozapine: evidence from a therapeutic drug monitoring service. Ther Drug Monit 1994; 16(4): 368-74. 3. Pirmohamed M, Williams D, Madden S et al Metabolism and bioactivation of elozapine by human liver in virro. J Pharmacol Exp Ther 1995 Mar; 272(3): $984-90$.

4. Von Moltke LL, Greenblatt DJ, Cotreau-Bibbo MM et al. Inhibitors of alprzolam metabolism in vitro: effect of serotonin-reuptake inhibitor antidepressants, ketoconazole and quinidine. Br J Clin Pharmacol 1994; 36 $615-6$

5. Dahl M, Llerena A, Bondesson U et al. Disposition of clozapine in man: lack of association with debrisoquine and $S$-mephenytoin hydroxylation of association with debrisoquine and $S$-mephen

6. Taylor D (Chief Pharmacist) Bethlem and Maudsley NHS Trust, Honary Lecturer, Institute of Psychiatry (personal communication).

\section{RE: False Memory Syndrome - Balancing the evidence for and against}

Sir - Following publication of this paper, I have been asked whether I would care to comment further in the light of the recent Brandon Report, which has been published since my paper was accepted. (Brandon et al 1998)

Most of the conclusions and recommendations of the Brandon Report will be endorsed by the psychiatric profession. Both the report and my paper emphasise that we have a responsibility not to cause harm to patients or their families.

The Report makes the following statements:

"There can be no justification for the use of memory recovery techniques which involve significant departure from normal interview or psychotherapy techniques".

It adds, "Great caution is needed if memory is reported after years of apparent amnesia. There is considerable evidence that such memories cannot be relied upon". It goes on to make extremely helpful recommendations regarding interview procedures.

Both the Brandon Report and my own paper emphasise that if accounts of sexual abuse in childhood are to be believed, then there must be corroborative evidence. It is deplorable that so many families have been harmed by the 'discovery' of previous sexual abuse, when no such abuse has occurred.

The difference in view point between the Brandon Report and my paper is this. The Report states, "given the prevalence of childhood sexual abuse, even if only a small proportion are repressed and only some of them are subsequently recovered, there should be a significant number of corroborated cases. In fact there is none".

I quoted one or two cases at length in my paper. This was to emphasise that even if there are only one or two well documented cases, this would prove that sexual abuse may indeed occur, be forgotten, and subsequently be recalled. It is my opinion that this happens although probably rarely.

Extreme caution needs to be exercised before any accounts of sexual abuse which are 'remembered during therapy' are believed, and definite corroborative evidence should always be obtained where possible. It will be interesting to see if further well documented cases come to light.

Stephen Critchlow, MRCPsych,
Specialist Registrar in Psychiatry, Down Lisburn Trust, Downshire Hospital, Ardglass Rd, Downpatrick, Co Down BT30 6RA, Northern Ireland.

\section{References}

1. Brandon S, Boakes J, Glaser D et al. Recovered memories of childhood sexual abuse. Implications for clinical practice. Brit J Psychiatry 1998; 172: 296-307. 2 . Critchlow S. False Memory Syndrome - balancing the evidence for and against. Ir J Psych Med 1998; 15(2): 64-7.

\section{False Memory Syndrome}

Sir-Dr Critchlow is to be congratulated on his effort to balance the evidence in this difficult area (IJPM June 1998). It is an issue that will continue to be debated for many years. The most important fact for psychiatrists to grasp is that false memories of childhood abuse can be induced and often the results cause great suffering in families and in the 'victim'. There are some techniques which are particularly likely to result in false memories, most of them discredited techniques and these will be avoided by sensible doctors. ${ }^{.}$What is not always recognised is that in any therapeutic relationship the therapist may inadvertently communicate his/her beliefs and expectations to the subject. Public and professional education can bring about dramatic changes. The so called epidemic of recovered or false memories seems to have come to an end in the USA though whether this is due to the successful litigation against therapists or widespread professional and media attention remains uncertain. ${ }^{2}$ We have a clear duty to avoid the creation of false memories but we must also treat with respect and concern anyone who presents with a story of childhood abuse. Where these are memories recovered after a long period of amnesia then an element of scepticism is justified but psychotherapy rather than confrontation is then called for.

Sydney Brandon, MD, FRCP, FRCPsych, DPM, DCH, 19 Holmfield Road, Leicester LE2 1SD, England.

\section{Fatal pharmacokinetic interaction involving amitriptyline combined with valproate and clozapine}

Sir - The purpose of this case history is to draw attention to the possible fatal consequences of combining amitriptyline with valproate and clozapine.

A physically healthy young adult male was diagnosed as suffering from schizophrenia in 1993. This was complicated at times by a significantly depressed affect which required antidepressant medication.

Following failure to respond to standard antipsychotic medication he was commenced on clozapine, with some clinical improvement. However he experienced epileptiform-like phenomena which were confirmed by an EEG. Consequently the dose of clozapine was reduced to $200 \mathrm{mg}$ bd and prophylactically he was commenced on valproate $500 \mathrm{mg}$ bd, which appeared to successfully alleviate this side-effect. During this time he continued to receive 
amitriptyline $150 \mathrm{mg}$ for depression. Serum valproate levels were within the normal range. He remained stable on these three drugs for approximately 18 months. Unexpectedly and tragically he experienced a grand mal seizure from which he appeared to recover, but subsequently was found dead a number of hours later. A post-mortem showed no physical cause of death. Toxicology however revealed an amitriptyline blood concentration of $1.5 \mu \mathrm{g} / \mathrm{ml}$. Although interpretation of the post mortem blood amitriptyline concentrations is complex ${ }^{1}$ cardiotoxicity can result with tricyclic antidepressant blood concentration in excess of $1.0 \mu \mathrm{g} / \mathrm{ml} .^{2}$ Such toxicity can begin insidiously, continue silently and become only clinically apparent in a sudden life threatening manner. ${ }^{2}$ A careful review of the patient's mental state and behaviour around the time of his death shows no indication of suicidal risk nor that he consumed all overdose of amitriptyline.

This raises the possibility of a pharmacokinetic interaction resulting in a cardiotoxic level of amitriptyline. Valproate significantly effects the pharmacokinetic disposition of amitriptyline, with a $30 \%$ increase in amitriptyline area wider the curve, which may result from the combined effect of decreased first-pass metabolism and inhibition of systemic metabolism. ${ }^{3}$ There is no information on a possible pharmacokinetic interaction between amitriptyline and clozapine. The possibility is suggested by the reported case ${ }^{4}$ of a significant increase (from $93 \mathrm{ng} / \mathrm{ml}$ to $185 \mathrm{ng} / \mathrm{ml}$ ) in nortriptyline blood concentration when clozapine was prescribed for a patient already taking nortriptyline $100 \mathrm{mg} /$ day. It was thought to have been a consequence of competitive inhibitions of CYP2D6 which is responsible for nortriptyline metabolism. This isoenzyme, along with others, is also involved in amitriptyline metabolism. ${ }^{5}$

In the case reported here the patient was prescribed two drugs (amitriptyline and clozapine) with the potential to cause epileptiform activity. When this occurred his dose of clozapine was reduced and commenced on Valproate, which is the anti-epileptic of choice as carbamazepine carries a haematological risk. For 18 months he remained well until he had a grand mal seizure. His death shortly afterwards may have been mediated by cardiac arrhythmia caused by cardiotoxic levels of amitriptyline and in turn by all insidious pharmacokinetic interaction.

Caution is therefore required when a tricyclic such as amitriptyline is simultaneously prescribed with valproate or clozapine, either singly or in combination. If such is ever clinically necessarily, then measuring plasma tricyclic concentrations is indicated.

Rory K Shelly, FRCPsych, Consultant Psychiatrist, St John of God Hospital, Stillorgan,

Co Dublin, Ireland.

References

1. Pounder DJ, Owen V, Quigley C. Post mortem changes in blood amitriptyline concentration. Am J Forensic Med Path 1994; 15: 224-30.

2. Preskorn SH. Tricyclic antidepressants: the whys and hows of therapeutic monitoring. J Clin Psychiatry 1989; 34(7): 34-42.

3. Wong SL, Cavanaugh J, Shi $\mathrm{H}$ et al. Effects of divalproex sodium on amitriptyline and nortriptyline pharmacokinetics. Clin Pharmacol Ther 1996; 60: $48-53$

4. Smith T, Riskin J. Effect of clozapine on plasma nortriptyline concentration. Pharmacopsychiatry 1994; 27: 41-2.

5. Bertz RJ, Granneman GR. Use of in vitro and in vivo data to estimate the likelihood of metabolic pharmacokinetic interactions. Clin Pharmacokinetics 1997; 32: 210-58.

\section{Epilim ${ }^{\circledR}$ Oral Prescribing Information}

Presentation: Epilim 200 Enteric Coated and Epilim 500 Enteric Coated: Entericcoated tablets containing $200 \mathrm{mg}$, and $500 \mathrm{mg}$ Sodium Valproate Ph.Eur. respectively. Epilim Crushable Tablets containing 100mg Sodium Valproate Ph.Eur. Epilim Syrup and Epilim Liquid (sugar-free) both containing 200mg Sodium Valproate Ph.Eur. per 5ml. Epilim Chrono 200, Epilim Chrono 300, and Epilim Chrono 500: Controlledrelease tablets containing a mixture of Sodium Valproate Ph.Eur. and Valproic Acid Fr.P. equivalent to $200 \mathrm{mg}, 300 \mathrm{mg}$, and $500 \mathrm{mg}$ Sodium Valproate respectively. Indications: Oral formulations of Epilim are indicated for all types of epilepsy. Dosage and administration: Adults: the dose should be titrated at three day intervals until seizure control is achieved. Initially $600 \mathrm{mg}$ a day increasing in steps of $200 \mathrm{mg}$ to a maximum dose of $2500 \mathrm{mg}$ per day. Children over $20 \mathrm{~kg}$ : initially $400 \mathrm{mg}$ a day increasing in steps to a maximum dose of $35 \mathrm{mg} / \mathrm{kg} /$ day. Children under $20 \mathrm{~kg}$ : initially $20 \mathrm{mg} / \mathrm{kg} /$ day - the dose may be increased in severe cases provided that plasma levels are monitored; above $40 \mathrm{mg} / \mathrm{kg} /$ day chemistry and haematology should be monitored. Epilim Chrono may be given once or twice daily. All other formulations should be given twice daily. Combination therapy: Levels of Epilim and co-administered anticonvulsants may be affected and optimum dosage is determined by seizure control. Contra-indications, Warnings, etc.: Contra-indications: Active liver disease, family history of severe liver disease, hypersensitivity to valproate. Sideeffects: Impaired hepatic function, particularly in children, occasionally leading to hepatic failure - treatment should be withdrawn in patients who suddenly develop symptoms compatible with hepatic disease such as nausea, anorexia, jaundice or malaise. Hyperammonaemia with or without hepatic dysfunction. Blood dyscrasia impaired platelet function, thrombocytopenia, occasional leucopenia and red cell hypoplasia. Occasionally increased appetite, weight gain, transient hair loss, behavioural disturbances, alterations to the menstrual cycle and pancreatitis. Symptoms of intoxication include ataxia, tremor, and stupor. Drug interactions: Epilim has significant interactions with phenytoin, lamotrigine and other anticonvulsants. Epilim may potentiate the effects of neuroleptics, MAOIs and other antidepressants. anticoagulants and salicylates. Cimetidine may inhibit the metabolism of Epilim. Epilim has no effect on the efficacy of oral contraceptives. Pregnancy: An increased incidence of congenital abnormalities has been demonstrated in offspring born to mothers with epilepsy both untreated and treated, including those treated with sodium valproate. Neural tube defects have been reported in about $1 \%$ of offspring of women who have received valproate during the first trimester of pregnancy. Pregnancies should be screened for neural tube defects by estimation of alpha-fetoprotein and ultrasound. Folate supplementation has been shown to reduce the incidence of neural tube defects in the offspring of high-risk women in general. Legal category: POM. Further information: Epilim is hygroscopic - tablets should not be removed from their foil until they are used. Epilim Chrono is recommended in cases where plasma valproate levels are being measured on account of its pharmacokinetics. The effective therapeutic range for valproate is $40-100 \mathrm{mg} / 1$ (278-694 micromol/1). Product Authorisation Numbers: Epilim 200 Enteric Coated 77/113/1, Epilim 500 Enteric Coated 77/113/2, Epilim 100mg Crushable Tablets 77/113/5, Epilim Syrup 77/113/4, Epilim Liquid 77/113/6, Epilim Chrono 200 77/113/9, Epilim Chrono $30077 / 113 / 8$, Epilim Chrono $50077 / 113 / 10$. Address: Sanofi Winthrop Ireland Ltd., United Drug House, Belgard Rd, Tallaght, Dublin 24.

Telephone: (01) 459 8877. Fax: (01) 4621855.

Epilim, Epilim Chrono and the Chrono device are registered trade marks. Date of preparation: 29 August 1996.

References: 1. Chadwick D., J. Neurol. Neurosurg. Psychiatry 1994; 57: 264-277. sanofi $\longrightarrow$ WINTHROP 2. Gillham R.A., Epilepsy Res., 1990; 7: 219-225. 